E Nuะsolese

MM Lepore

F Montagna

$\checkmark$ Marcario

$S$ De Rosa

$B$ Solarino

G Di Vella

\section{Child abuse and dental neglect: the dental team's role in identification and prevention}

\section{Authors' affiliations:}

E Nuzzolese, Forensic Odontologist, Bari, Italy

MM Lepore, V Marcario, Dental Hygienists, Bari, Italy

F Montagna, Department of Oral and Dental Diseases and Orthodontics, University of Cagliari, Cagliari, Italy

$S$ De Rosa, Paediatric Dentist, Matera, Italy B Solarino, G Di Vella, Department of Forensic Pathology, Sezione di Medicina Legale, University of Bari, Bari, Italy

\section{Correspondence to:}

\section{Emilio Nuz:olese}

Viale John F Kennedy 77

70124 Bari, Italy

Tel.: +390805042555

Fax: +3908022031198

E-mail: emilionu@tin.it

\section{Dates:}

Accepted 3 June 2008

\section{To cite this article:}

Int J Dent Hygiene 7, 2009; 96-101

DOI: $10.1111 / \mathrm{j} .1601-5037.2008 .00324 . x$

Nuzzolese E, Lepore MM, Montagna F, Marcario V, De Rosa S., Solarino B, Di Vella G. Child abuse and dental neglect: the dental team's role in identification and prevention.

(c) 2009 The Authors.

Journal compilation (๑ 2009 Blackwell Munksgaard

\begin{abstract}
Health, education and social services are placing increasing emphasis on preventing abuse and neglect by early intervention to support families where children and young people may be at risk. Dental hygienist and dental assistants, like all other health professionals, can have a part in recognizing and preventing children from those who would cause them harm. They should be aware of the warning signs, recognizing what to consider as abuse or dental neglect and know how to deal with these young patients, and to fulfil their legal and ethical obligation to report suspected cases. The purpose of this report is to review the oral and dental aspects of child abuse and dental neglect thus helping the dental team in detecting such conditions. In particular, this report addresses the evaluation of bite marks as well as perioral and intraoral injuries, infections, early childhood caries and diseases that may be indicative of child abuse or neglect. Emphasis is placed on an appropriate protocol to follow in the dental practice to best treat and protect children who may have suffered abuse, helping the team in the diagnosis and documentation.
\end{abstract}

Key words: child abuse; dental assistant; dental hygienist; dental neglect; forensic odontology

\section{Introduction}

The abuse and neglect (or maltreatment) of children is a worldwide problem, although its manifestations and extent vary. It is far more prevalent than is generally recognized. Childrens' rights are defined by the United Nations Convention on the Rights of the Child 1989. This is an international human rights treaty that applies to all children and young people under the age of 18 years (1).

96 | Int J Dent Hygiene 7, 2009; 96-101 
Scientific literature offers little in the line of guidance as to what a dental hygienist can perform in specific areas of forensic science. The dental hygienist's role may be described as a set of defined functions in the field of oral health. This is not to suggest that the role involves no more than the execution of limited responsibilities. The same could be said of the dental assistant. In fact, dental hygienist and dental assistant can play an important part in the complex area of child abuse and neglect (2). One reason for this is the likelihood that they are one of the first health professionals to come in contact with the presumed victim of the abuse and help create an atmosphere of trust in which the patient feels able to 'open up'. This is mainly because they are able to spend more time with the patient than the dentist (3).

Physical abuse by parents or caregivers includes beatings, shaking, scalding and biting. Although some forms of corporal punishment are widely accepted, many people think of any injury beyond immediate redness as abuse. However, signs of physical abuse might not be immediately evident although they must have a systematic nature in order to be considered as possible maltreatment.

Child neglect is omission of care, such as health care, education, supervision, protection from environmental hazards, not meeting physical or emotional needs resulting in actual or potential harm. Neglect, from a child's perspective, is also not adequately meeting his basic needs, regardless of the reasons. Several factors can contribute to neglect, such as parental depression, a child's disability, family violence or an absence of community resources. Recognizing the problems underpinning neglect helps interventions to be tailored to the specific needs of the child and family $(4,5)$.

Dental hygienists and dental assistants, like all other health professionals, can have a part in recognizing child abuse and most of all dental neglect, during their everyday work. The level of competency required and the closely interrelated activities of evaluation and research have resulted in the recognition of dental hygiene as a health profession which not only meets oral health needs but also medico-legal responsibilities.

Authors experience with the local dental community and Pediatric Hospital 'Papa Giovanni XXIII' in Bari (Italy) highlight low levels of awareness of potential abuse on children and disabled, among health professionals.

\section{Non-accidental lesions}

Domestic violence and abuse of minors can be described as situations in which traumatic injuries found are not accidental. They may be skin lesions resulting from the use of belts or other objects or bites made with the intention of causing harm. Physical abuse may also involve hitting, shaking, throwing, burning, drowning and suffocating. Pathological presentations of minimal clinical relevance such as irritations, bruises, scratches and abrasions may in fact provide legitimate grounds for suspicion, or even certainty of the occurrence of abuse (Figs 1-3) (5-10). It is assumed that the child is fully dressed during a dental examination. Nevertheless, areas like the side of the face, ears, neck, top of shoulders and forearms, should

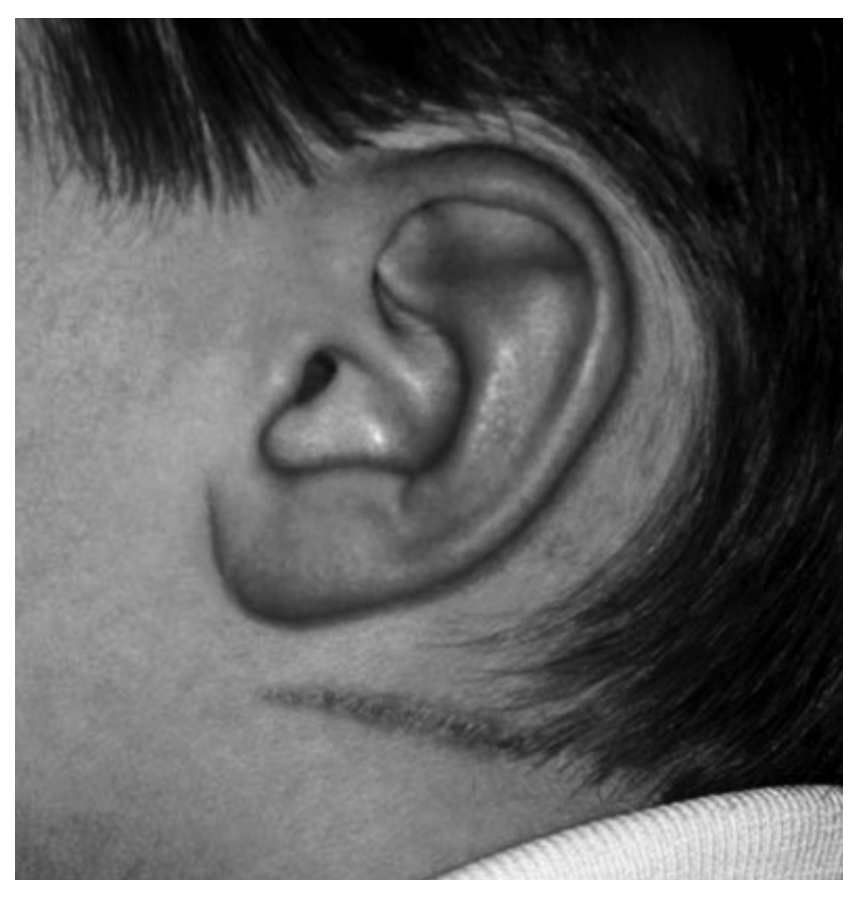

Fig. 1. Burn on the side of the neck of boy in an unusual site for an accidental injury (modified from child protection and the dental team, COPDEND 2006, Harris J, Sidebotham P, Welbury R et al., pp. 2-4).

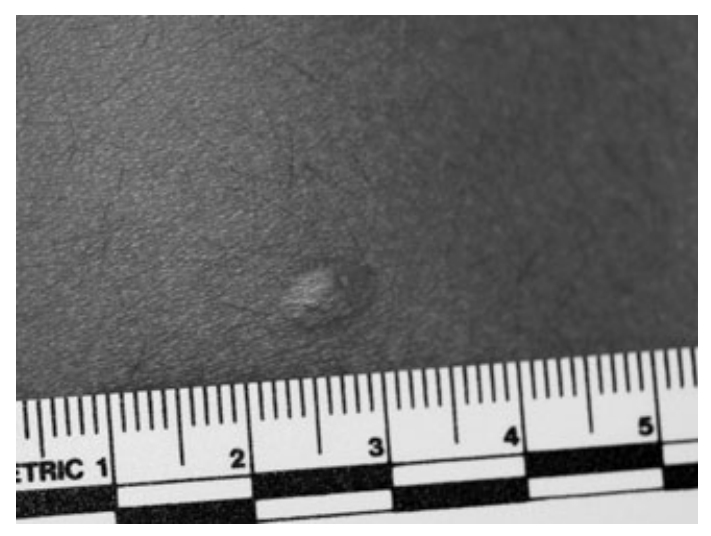

Fig. 2. Cigarette burn on the superior arm of a girl, abused by her father. 


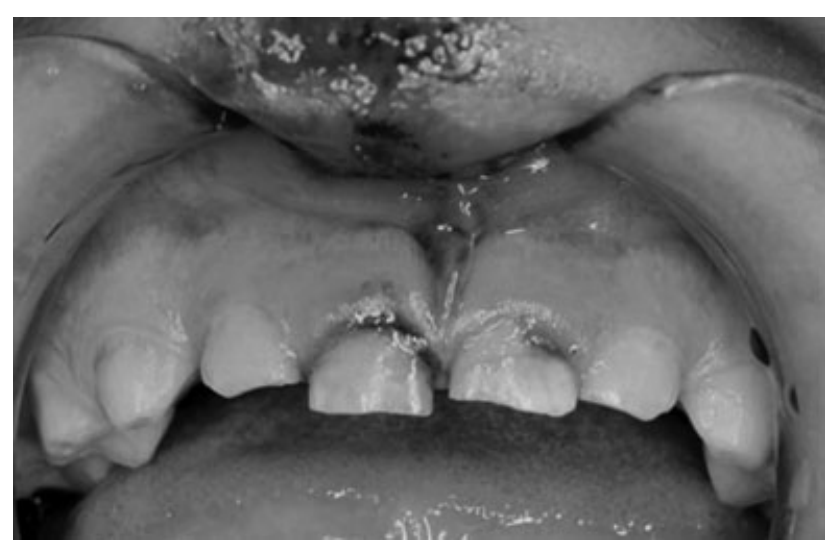

Fig. 3. Torn and bruised frenum and upper lip in association with other accidental dental and oral injuries in a child (modified from Child protection and the dental team, COPDEND 2006, Harris J, Sidebotham P, Welbury R et al., pp. 2-6).

be explored during a dental checkup when there is a suspicion of abuse (11). The detection and identification of skin lesions constitutes a basic step to be performed before they lose their medico-legal value or significance.

Some injuries may be reported by parents/teachers as accidental but are in fact bite marks. The correct identification of non-accidental lesions may permit and/or contribute to the demonstration of abuse arising from a violent interaction between individuals. Bite lesion examples in USA approximately $1 \%$ of all visits to the hospital Emergency Room are related to bite wounds. In this setting, human bites come third in prevalence, after dog and cat bites (12).

However, unintentional or accidental injuries to the mouth are common and must be distinguished from abuse by judging whether the history, including the timing and mechanism, is consistent with the characteristics of the injury and also the child's developmental stage. Multiple injuries, injuries at different stages of healing, or of a discrepant history should arouse a suspicion of abuse. Consultation with a dentist and other healthcare providers, such as social workers and psychologists, is always helpful and advisable. One should take into account, in fact, that there is a whole field of literature in behavioural science which should be also explored but is beyond the scope of this article.

\section{Bite marks}

Bite marks should be suspected when ecchymoses, abrasions or lacerations are found in an elliptical or ovoid pattern (Fig. 4). Bitemarks may have a central area of ecchymoses (contusions) caused by two possible phenomena: positive pressure from the
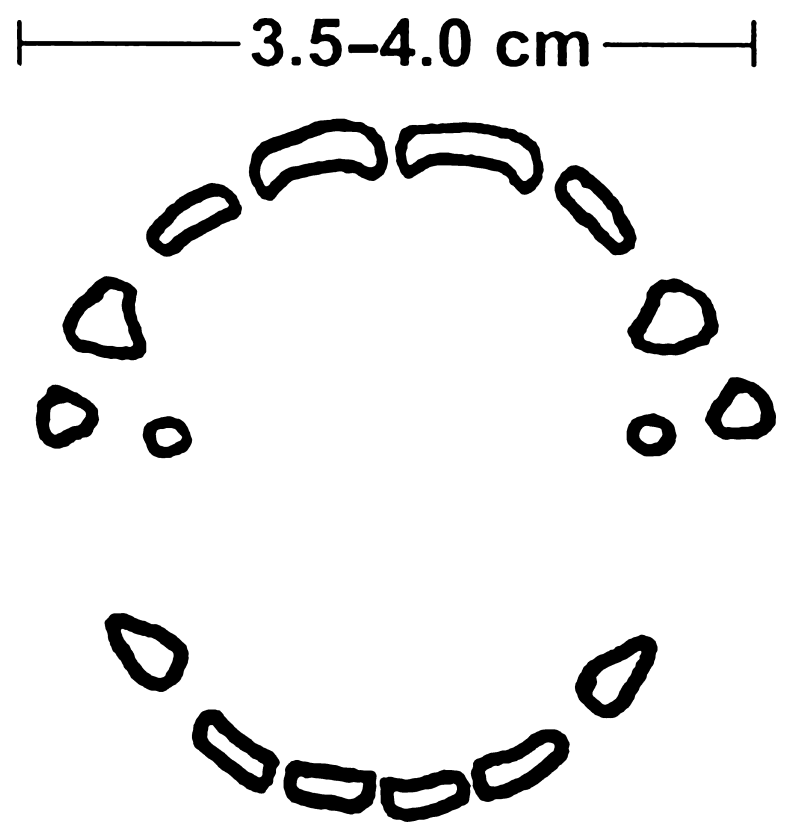

Fig. 4. Typical bitemark pattern.

closing of the teeth with disruption of small vessels; or negative pressure caused by suction and tongue thrusting (13). Bites produced by dogs and other carnivorous animals tend to tear skin. Whereas, human bites compress flesh and can cause abrasions, contusions and lacerations but rarely avulsions of tissue. An intercanine distance measuring more than $3.0 \mathrm{~cm}$ is suspicious of an adult human bite (Fig. 4) (3).

The dental hygienist may be involved in the documentation of one or more bitemarks where he/she can independently identify lesions of a traumatic nature on the orofacial region and the uncovered skin of the neck, shoulder and arm of the patient during treatment. Such lesions may represent potential bites that suggest abuse of minors. It will then be his/her responsibility to report it to the law enforcement authorities. If the suspected episode of abuse has occurred within the preceding $72 \mathrm{~h}$, a medical examination must be performed as soon as possible, because within that period of time it is still possible to collect samples that carry evidentiary value.

Photographic documentation of the injury should include the use of a millimetric reference scale (Fig. 5). For practical reasons as well as the benefit of verification, archivation and transmission of the photos, we feel that using a digital camera of semi-professional quality is adequate. A tag with the date and reference number and the millimetric reference scale should be placed close to the area to be photographed. The reference scale most widely used and accepted by forensic odontologists is the no. 2 ruler of the American Board of Forensic Odontologists (14-16) (Fig. 6). 


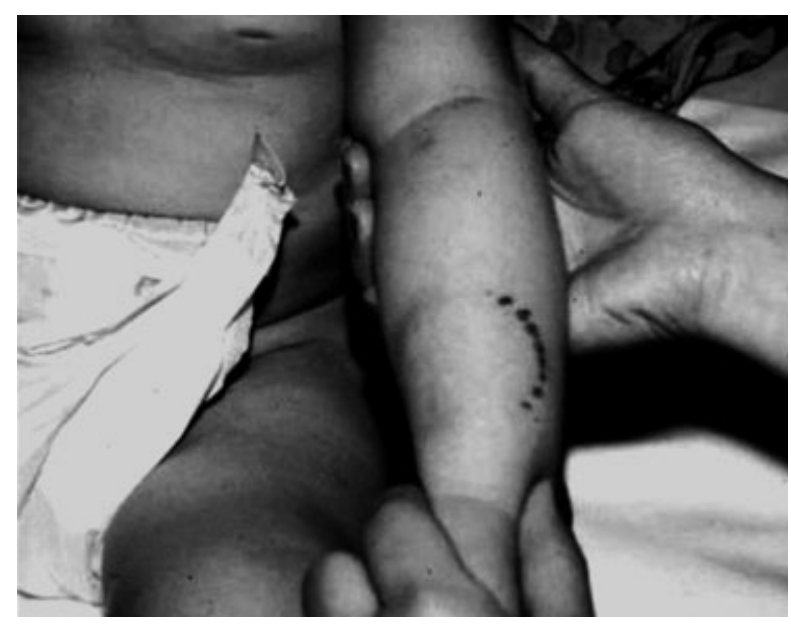

Fig. 5. Bitemark on a child as sign of abuse (reproduced with the permission of Dr Normann P. Sperber, San Diego, CA, USA).

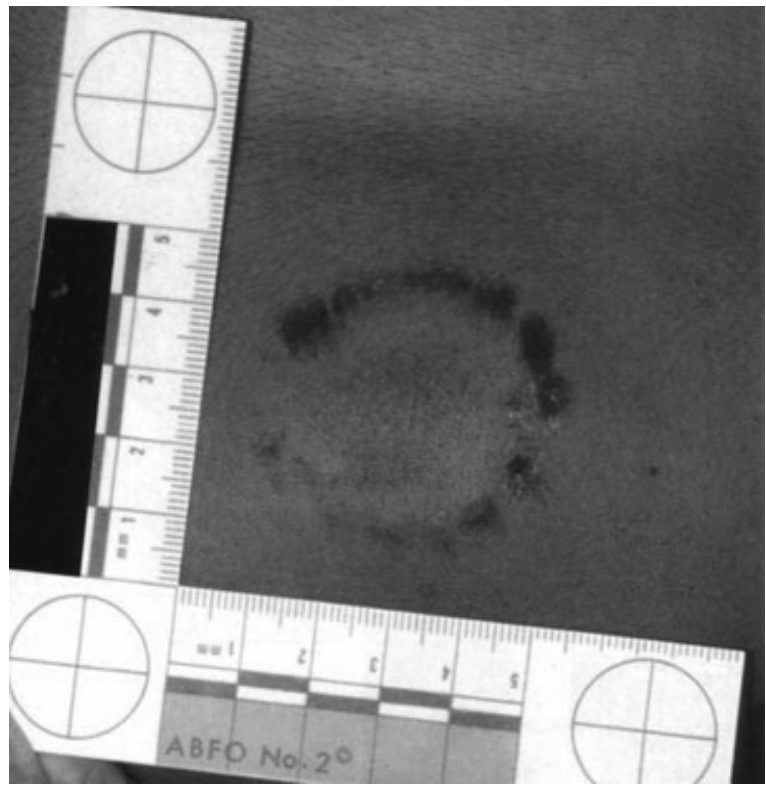

Fig. 6. Injury photographic documentation with the millimetric reference scale (no. 2 ruler of the American Board of Forensic Odontologists).

Even if saliva and cells have dried, they should be collected using the double-swab technique. First, a sterile cotton swab moistened with distilled water is used to wipe the area in question, dried, and placed in a specimen tube. A second sterile dry cotton swab cleans the same area, then is dried and placed in a specimen tube. A third control sample should be obtained from an uninvolved area of the child's skin. All samples should be sent to a certified forensic laboratory for prompt analysis.

In addition to photographic evidence, every bite mark that shows indentations should have a polyvinyl siloxane impres- sion made immediately after swabbing the bite mark for secretions containing DNA (17). This impression will help provide a three-dimensional model of the bite mark. Written observations and photographs should be repeated daily for at least 3 days to document the evolution of the bite.

\section{Child neglect}

Another form of abuse of minors is the act of abandonment or the omission of protection, support or care, thereby exposing the minor to harm. The actions against the victim do not involve physical infliction of pain. Rather they are the conduct of the parent or guardian of the minor resulting in nutritional deficits and omissive behaviour such as negligence and neglect, including necessary medical and dental care (17). Dental neglect, as defined by the American Academy of Pediatric Dentistry is the "wilful failure of parent or guardian to seek and follow through with treatment necessary to ensure a level of oral health essential for adequate function and freedom from pain and infection' (18).

In other words, a crime of 'endangerment' is present, which the legislature has placed between crimes against life and the safety of the individual for the purpose of protecting the safety of persons of a specific age or those caught in particular situations and as a result are more vulnerable.

However, many adults visit the dentist only when in pain for emergency treatment and choose not to return for treatment to restore complete oral health. This behaviour is sometimes the consequence of poor attention to self and professional oral care but can also be a consequence of financial difficulties in accessing dental services. Access to dental treatments is, in fact, is some Countries not covered by the

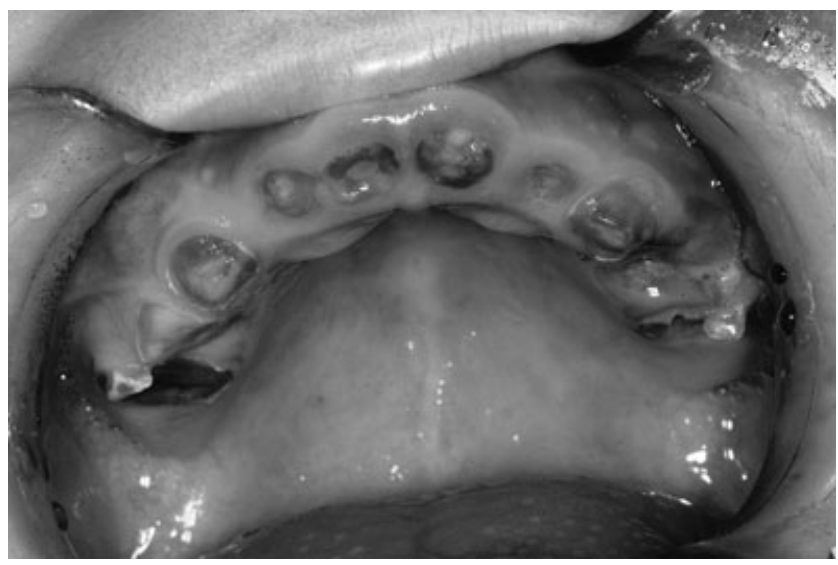

Fig. 7. Example of dental neglect: baby bottle caries - early childhood caries (Reproduced with the permission of Prof. I. Cukovic-Bagic, Zagreb, Croatia) 
national health system. However, they may adopt the same attitude for their children. The result of this behaviour can be particularly painful in children affected by dental caries (severe early childhood caries formerly termed 'baby bottle' or 'nursing' caries), periodontal diseases, and other oral conditions, left untreated (Fig. 7) (11).

\section{Role of dental team}

The modern concept of health as defined by the World Health Organization, is a state of physical, mental and social wellbeing and not merely the absence of disease or infirmity. This is particularly important when dealing with children and the vulnerable.

Dental hygienists and dental assistants are a key health professions in the effective management of the dental patient, especially in the initial stages (prevention) and subsequent to the intervention of the specialist (maintenance). They may also be involved in supporting medico-legal investigative activities of a forensic odontologist. This is not to say they can act unilaterally in the area of medico-legal activities. However, the obligation to submit a report to law enforcement authorities remains (19). In particular, non-accidental skin lesions such as bitemarks may constitute the first key step of a procedure designed to record the injury in time as evidence. This is particularly crucial given the nature of bitemarks and less severe injuries $(20,21)$.

The prevention and diagnosis of child abuse is usually undertaken by a paediatrician. The dental team has an important role to play however as the head and neck are the areas most often targeted.

The responsibilities of the health professionals in the dental sector may be summarized as recognizing, recording and reporting of the suspected abuse. The objective is to promote a trusting relationship, discussing neutral topics and those of interest to the minor (school, sport and hobbies) in order to get him/her to feel at ease and relax, thereby allowing the child to speak openly. For these reasons, it is important to provide an atmosphere of security and protection, minimizing sources of disturbance within the office.

The dental hygienist and dental assistant may observe cases of child neglect in routine professional practice and in some cases may be the first health professional to make contact with the victim. In particular, the dental hygienist can play a highly important part in the complex area of child abuse and neglect. Principally because they are one of the first medical professionals to come in contact with the presumed victim and can form a trusting relationship and obtain information from them which may give rise to a suspicion of abuse, especially because they are able to spend more time with the patient than the dentist in speaking. This approach will also allow data collection on the type of patient and the family background, but, most importantly, develop an effective treatment programme and obtain better compliance from the child (22).

If the parents have repeatedly been alerted to the nature and extent of the child's condition and notwithstanding this take no action, at this point the health professionals should consider reporting neglect.

In some cases parents' lack of knowledge on dental diseases and dietary habits or even oral hygiene measures cannot be equated with wilful neglect of a child. If, despite these efforts, the parents fail to seek therapy, the case should be reported to the appropriate child protection agency. However, to avoid misunderstanding, it is advisable to use the term 'dental neglect' for situations where there is a failure to respond to a known significant dental problem, as this is an area that requires forensic background, sensitivity and clinical judgement.

\section{Conclusion}

The dental team can be an important resource in the field of child abuse and dental neglect as they could identify not only physical signs but also psychological and emotional behaviour that may be clues to possible abuse. For this reason they should be knowledgeable about such findings and their significance and meticulously monitored and recorded.

However, in order to avoid misunderstandings and increase sensitivity, the authors recommend increased awareness and more training for dentists, dental hygienists and dental assistant in the area of behavioural and forensic science.

\section{References}

1 United Nations, Convention on the Rights of the Child. Geneva, Switzerland: Office of the High Commissioner for Human Rights, 1989. Available at http://www2.ohchr.org/english/law/crc.htm.

2 Mouden LD. Child abuse and neglect: the dental assistant's role in prevention. Dent Assist 2000; 69: 30-37.

3 Nuzzolese E, Lepore MM, Marcario V. Legal bitemark evaluation: issues for the dental hygienist (article in italian), Prevenzione $\&$ assisten:a dentale 2008; 3: 15-19.

4 American Academy of Pediatrics, Committee on Child Abuse. Guidelines for the evaluation of sexual abuse of children: a subject review. Pediatrics 1999; 103: 186-191.

5 Mouden LD, Bross DC. Legal issues affecting dentistry's role in preventing child abuse and neglect. J Am Dent Assoc 1995; 126: 1173-1180.

6 Schwartz S, Woolridge E, Stege D. The role of the dentist in child abuse Quintessence Int 1976; 7: 79-81. 
7 Baetz K, Sledziewski W, Margetts D, Koren L, Levy M, Pepper R. Recognition and management of the battered child syndrome. J Dent Assoc S Afr 1977; 32: 13-18.

8 Jessee SA. Physical manifestations of child abuse to the head, face and mouth: a hospital survey. J Dent Child 1995; 62: 245-249.

9 Vadiakas G, Roberts MW, Dilley DC. Child abuse and neglect: ethical issues for dentistry. J Mass Dent Soc 1991; 40: 13-15.

10 Naidoo $S$. A profile of the oro-facial injuries in child physical abuse at a children's hospital. Child Abuse Negl 2000; 24: 521-534.

11 Pretty IA, Sweet D. Anatomical location of bitemark and associated finding in 101 cases from United States. J Forensic Sci 2000; 45: 812.

12 Herschaft E.E., Alder M.E., Ord D.K., Rawson R.D., Smith E.S. Bite mark analysis. In: Herschaft E.E., Alder M.E., Ord D.K., Rawson R.D., Smith E.S., eds. Manual of Forensic Odontology, 4th edn. New York, American Society of Forensic Odontology, 2006, pp. 173-176.

13 Dorion RBJ. Bitemark Evidence. New York, Marcel Dekker, 2005.

14 Mark L. Bernstein, nature of bitemarks. In: Dorion RBJ, ed. Bitemark Evidence. New York. Mercel Dekker, 2005, p. 63.
15 Bowers C. Michael, Forensic Dental Evidence. San Diego, California, USA, Elsevier, 2004.

16 Benson Bw, Cottone JA, Bomberg TJ, Sperber ND. Bitemark impression: a review of techniques and materials. J Forensic Sci 1988; 33: 1238.

17 Harris J, Sidebotham P, Welbury R et al. Child protection and the dental team, the Committee of Postgraduate Dental Deans and Directors, COPDEND. 2006: 2.1.

18 American Academy of Pediatric Dentistry. Definition of dental neglect. Pediatr Dent 2003; 25 (Suppl.): 7.

19 Dubowitz H, Bennett S. Physical abuse and neglect of children. Lancet 2007; 369: 1891-1899.

20 Sfikas PM. Reporting abuse and neglect. JADA 1999; 130: $1797-$ 1799.

21 Kenney JP. Domestic violence: a complex health care issue for dentistry today. Forensic Sci Int 2006; 159S: S121-S125.

22 Sperber ND. Bite marks, oral and facial injuries: harbingers of severe child abuse? Pediatrician 1989; 16: 207-211. 